\title{
Ecological and physiological assessment of adaptation processes of nonresident students to the anthropogenic conditions of Moscow
}

\author{
Yana Majorova ${ }^{*}$, Dilyara Efremova ${ }^{2}$, Alexander Severin ${ }^{1}$, Vasily Shevtsov ${ }^{1}$, \\ Konstantin Isaev ${ }^{1}$, Bogdan Laver ${ }^{3}$, Md Shamsher Alam ${ }^{4}$ \\ ${ }^{1}$ Peoples Friendship University of Russia (RUDN University), Faculty of Ecology, 6 Miklukho- \\ Maklaya Street, Moscow, 117198, Russian Federation \\ ${ }^{2}$ Russian State University for the Humanities, Moscow, 125993, Russia \\ ${ }^{3}$ Academy of Postgraduate Education of the Federal Scientific and Clinical Center of the Federal \\ Medical and Biological Agency of Russia, Moscow, 115682, Russia \\ ${ }^{4}$ Interactive Research and Development (IRD), Dhaka 1212, Bangladesh
}

\begin{abstract}
The article provides an ecological and physiological assessment of the adaptation of nonresident students to the anthropogenic conditions of the metropolitan metropolis. The complex of environmental factors (socioeconomic, ecological and anthropogenic factors) that play a significant role in the dynamics of adaptation of students is considered. The analysis of the obtained data showed that a complex of environmental factors of a large city causes a violation of the rhythm of sleep and wakefulness and the level of personal and situational anxiety. The presented complex of stress factors in general has a significant impact on the mental health of nonresident students, which is manifested in a high level of personal and situational anxiety and deterioration of the functional state of the autonomic nervous system. All this in general led to mental discomfort and to overstrain the adaptation processes of nonresident students of different courses.
\end{abstract}

\section{Introduction}

It is a well-known fact that the health of an individual in the process of ontogenesis is influenced by a complex of bio-social factors (heredity, natural-climatic, anthropogenic, environmental conditions and quality, etc.). The conceptual foundations of multi-factory make it possible to create scientifically based approaches to assessing the norm of psychosomatic human health [1]. A person's health status is formed within the boundaries of a certain ecological and social system. In this regard, to determine the cause-and-effect relationships of the occurrence of diseases, it is important to know the characteristics of the human environment [2].

Therefore, an important aspect in assessing the multifactorial nature of the environment is those studies that are aimed at studying the ecological and physiological characteristics

\footnotetext{
*Corresponding author: kuzmina.gtmost@mail.ru
} 
of the human body. Recently, research related to the study of the complex adaptation of young students, in particular nonresident students who leave for other cities and countries to study, has become relevant in this direction. The study of the peculiarities of the ecological and physiological processes of adaptation of the functional systems of the body of nonresident students is an important scientific and applied task of the society $[3,4]$. Based on the above, we set the goal to conduct a study on the ecological and physiological assessment of the adaptation processes of nonresident students to the anthropogenic conditions of the metropolitan metropolis of Russia [5].

\section{Materials and methods}

The presented study was conducted on the basis of two laboratories ("Environmental Psychology" and "Environmental Medicine") of the Department of Forensic Ecology with the course of Human Ecology of the Faculty of Ecology and the Department of Normal Physiology of the Medical Institute of the Peoples' Friendship University of Russia (RUDN). It is important to note that such comprehensive scientific research aimed at studying the adaptation of students of the university has been carried out almost since its foundation (1960).

The sample of students consisted of 210 students of the preparatory, first and third courses (130 girls and 90 boys) of different nationalities, who came from different regions of Russia: (Moscow region, the Center of Russia, the Volga region, the North Caucasus and Siberia). Students of the environmental, agricultural, humanitarian, social and engineering faculties took part in the study.

Comprehensive testing of the students' anxiety level was carried out according to the approved Spielberg-Hanin method [6]. Physiological assessment of the Cardiovascular system of nonresident students was carried out using a certified hardware and software complex "Psychophysiologist" (LLC "Medikom", Taganrog).

According to the generally accepted standards of the cardio logical scientific society, the following heart rate indicators were analyzed [7]:

-Heart rate (beats per minute) - heart rate-statistical characteristics of the dynamic series of cardiac intervals;

- HF-the power of high-frequency oscillations in the range of $0.4-0.15 \mathrm{~Hz}$, reflects the level of activity of the parasympathetic link of regulation;

- LF-the power of low-frequency oscillations of the duration of RR intervals in the range of $0.15-0.04 \mathrm{~Hz}$, reflects the level of activity of the vasomotor center.

VLF - very low frequency, slow waves. Their oscillation frequency is less than $0.04 \mathrm{~Hz}$.

To assess the impact of a complex of socio-economic and environmental factors on the study sample of nonresident students, a questionnaire was conducted.

The test of the studied sample by the Kolmogorov-Smirnov criterion showed the normality of the sample distribution (large sample size $\geq 50$ ).

All the data obtained were processed statistically using the Statistica 6.0 package (StatSoft. Inc., USA). The level of differences was considered statistically significant at $\mathrm{p}<$ 0.05 .

The research followed all the ethical principles of conducting research involving people as subjects in accordance with the Helsinki Declaration. Participation as study subjects was voluntary and anonymous. Informed consent was obtained from all participants [8].

\section{Results}

The survey data on the most common problems of adaptation showed (Table. 1) that the 
dynamics of the adaptation process of nonresident students is influenced by a complex of socio-economic, environmental factors and individual typological characteristics of the student.

Table 1. Analysis of the obtained data of the survey of nonresident students on the assessment of the complex of environmental factors of the metropolitan metropolis $(n=210)$

\begin{tabular}{|c|c|c|c|c|c|c|c|c|c|c|}
\hline \multirow{3}{*}{$\begin{array}{l}\text { Cours, } \\
\text { age } \\
\text { (years) }\end{array}$} & \multirow[t]{3}{*}{ Gender } & \multicolumn{9}{|c|}{ The most common socio-economic and psychological problems, $\%$} \\
\hline & & \multicolumn{3}{|c|}{ Socio-economic } & \multicolumn{3}{|c|}{ Environmental } & \multicolumn{3}{|c|}{ Psychological } \\
\hline & & $\begin{array}{l}\text { Search } \\
\text { for } \\
\text { housing }\end{array}$ & $\begin{array}{l}\text { Lack of } \\
\text { funds }\end{array}$ & $\begin{array}{c}\text { Combining } \\
\text { study and } \\
\text { work }\end{array}$ & Noise & $\begin{array}{l}\text { Gas } \\
\text { polluti } \\
\text { on }\end{array}$ & $\begin{array}{c}\text { Sleep } \\
\text { proble } \\
\text { ms }\end{array}$ & \begin{tabular}{|c|} 
Making \\
independent \\
decisions
\end{tabular} & $\begin{array}{c}\text { Difficulties of } \\
\text { interpersonal } \\
\text { communication }\end{array}$ & $\begin{array}{c}\text { Level of } \\
\text { mental } \\
\text { health* }\end{array}$ \\
\hline \multirow{2}{*}{$\begin{array}{l}\text { Prepara } \\
\text { tory } \\
\text { Faculty }\end{array}$} & girls & 7 & 41 & 6 & 69 & 63 & 72 & 70 & 54 & 3 \\
\hline & boys & 4 & 63 & 11 & 50 & 42 & 63 & 78 & 51 & 4 \\
\hline \multirow{2}{*}{$\begin{array}{l}\text { 1st year } \\
(17-18)\end{array}$} & girls & 9 & 68 & 9 & 61 & 70 & 70 & 73 & 50 & 3 \\
\hline & boys & 3 & 83 & 14 & 33 & 40 & 64 & 75 & 47 & 2 \\
\hline \multirow{2}{*}{$\begin{array}{l}\text { 3-thd } \\
\text { year } \\
(17-18)\end{array}$} & girls & 23 & 54 & 31 & 27 & 41 & 59 & 28 & 35 & 3 \\
\hline & boys & 32 & 62 & 59 & 17 & 30 & 53 & 25 & 29 & 3 \\
\hline
\end{tabular}

Note:* Score in points : 1-minimum, 5-maximum

The analysis of the obtained data of the questionnaires of the studied sample revealed that the socio-economic difficulties of nonresident students were associated with financial problems (with a chronic lack of money), which was observed in all in different proportions (from $41 \%$ to $83 \%$ ). There were also difficulties associated with combining students ' studies and work (from $6 \%$ to $59 \%$ ). There were also problems related to finding and renting housing (from $7 \%$ to $32 \%$ ).

The influence of environmental and anthropogenic factors (traffic noise, chemical pollution of the urban atmosphere and disturbance of the rhythm of sleep and wakefulness) was also significant for all the nonresident students studied.

The adaptation process of the study sample of nonresident students was also influenced by psychological problems, for example, the willingness to make independent decisions, and often difficulties in interpersonal communication with classmates. The level of mental health of nonresident students was also subjectively assessed by nonresident students on 3 points (with the exception of young men from the preparatory faculty-4 points) from a maximum of 5 points.

The assessment of the heart rate variability (HRV) of nonresident students is presented in table 2 .

Table 2 Assessment of the functional state of students based on the results HRV, $(n=210)$

\begin{tabular}{|c|c|c|c|c|c|c|}
\hline \multirow{2}{*}{$\begin{array}{c}\text { Cours, age } \\
\text { (years) }\end{array}$} & Gender & \multicolumn{5}{|c|}{ Levels of the physiological state of VCM, \% } \\
\cline { 3 - 7 } & & Optimal & $\begin{array}{c}\text { Close to } \\
\text { optimal }\end{array}$ & Permissible & $\begin{array}{c}\text { Maximum- } \\
\text { permissible }\end{array}$ & Negative \\
\hline $\begin{array}{c}\text { Preparatory } \\
\text { Faculty } \\
(16-17)\end{array}$ & girls & 2 & 8 & 53 & 25 & 12 \\
\cline { 2 - 7 } & boys & 3 & 15 & 42 & 33 & 7 \\
\hline $\begin{array}{c}1 \text { st year } \\
(17-18)\end{array}$ & girls & 1 & 9 & 55 & 25 & 10 \\
\cline { 2 - 7 } & boys & 6 & 12 & 46 & 31 & 5 \\
\hline $\begin{array}{c}3-\text { thd year } \\
(17-18)\end{array}$ & girls & 0 & 10 & 40 & 28 & 8 \\
\cline { 2 - 7 } & boys & 0 & 1 & 60 & 31 & 22 \\
\hline
\end{tabular}


Evaluation of the heart rate variability of nonresident students showed that most of the subjects were in the physiological zone "permissible" (preparatory faculty girls $-53 \%$, boys - 42\%; first year girls -55 , boys - 46\% third year - 40\%, 60\%) and "maximum permissible" (preparatory faculty $-25 \%, 33 \%$; third year, girls- $40 \%$, boys-60\%). The results of the Spielberger-Hanin psychological test on personal and situational anxiety are presented in Table 3.

Table 3. Results of the Spielberger-Hanin psychological test on personal and situational anxiety $(\mathrm{n}=210)$

\begin{tabular}{|c|c|c|c|c|c|c|c|}
\hline $\begin{array}{c}\text { Cours, age } \\
\text { (years) }\end{array}$ & Gender & \multicolumn{2}{|c|}{ Level of personal anxiety, \% } & \multicolumn{2}{|c|}{ Level of situational anxiety, \% } \\
\cline { 2 - 8 } & high & medium & low & high & medium & low \\
\hline $\begin{array}{c}\text { Preparatory } \\
\text { Faculty } \\
(16-17)\end{array}$ & girls & 44 & 56 & 0 & 57 & 40 & 3 \\
\cline { 2 - 8 } & boys & 57 & 40 & 3 & 51 & 42 & 7 \\
\hline $\begin{array}{c}\text { 1st year } \\
(17-18)\end{array}$ & girls & 36 & 61 & 3 & 50 & 46 & 4 \\
\cline { 2 - 9 } & boys & 40 & 52 & 8 & 48 & 42 & 10 \\
\hline \multirow{2}{*}{$\begin{array}{c}\text { 3-thd year } \\
(17-18)\end{array}$} & girls & 40 & 45 & 5 & 40 & 52 & 8 \\
\cline { 2 - 8 } & boys & 49 & 50 & 1 & 32 & 60 & 8 \\
\hline
\end{tabular}

The analysis of the test data showed high and average values for personal anxiety of the subjects (preparatory faculty: girls $-44 \%$, boys $-57 \%$, first year: girls-36\%, boys- $40 \%$; third year: girls- $40 \%$, boys $-49 \%$ ). The same trend is observed for situational anxiety (preparatory faculty: girls $-57 \%$, boys $-51 \%$; first year: girls- $50 \%, 48 \%$; third year $-40 \%$, $32 \%)$.

Analyzing the results of research and literature data on the adaptation of students, it should be noted that significant difficulties for a nonresident student are associated with new living conditions and continued socialization at the university, which is associated with a new status of the student, a different system of education, complex relationships with other students and teachers, as well as difficulties in the social and cultural sphere. This is confirmed by the questionnaire data on frequently encountered socio-economic and ecological-psychological problems that significantly affect the dynamics of the adaptation process of nonresident students [9-13].

\section{Conclusions}

The results of our research show that the complex influence of a complex of environmental factors on the adaptation processes of nonresident students is accompanied by different dynamics of adaptation mechanisms. Ecological and physiological assessment of the adaptation of nonresident students to the anthropogenic conditions of the metropolitan metropolis causes a violation of the rhythm of sleep and wakefulness, at the level of personal and situational anxiety. The presented complex of stress factors in general has a significant impact on the mental health of nonresident students, which is manifested in a high level of personal and situational anxiety, deterioration of the level of the functional state of the autonomic nervous system. This, as a rule, causes mental discomfort and leads to overstrain of the adaptive potential of nonresident students. 


\section{References}

1. N. A. Aghajanyan, V. I. Petrov, I. V. Radysh, S. I. Krayushkin, Chronophysiology, chronopharmacology, and chronomedicine (Publishing house of VolGMU, Volgograd, 2005)

2. Ya.V. Kuzmina, V.V. Glebov, The World of Science, Culture and Education, 6-2(25), 305-307 (2010)

3. R.M. Baevsky, Analysis of heart rate variability in the use of various electrocardiographic systems: methodological recommendations. (Moscow, 2002)

4. A. E. Severin, V. I. Torshin, O. V. Mankayeva, N. Mansur, Ecological and physiological problems of adaptation Materials of the XVII All-Russian Symposium, 194-195 (2017)

5. Y. Mayorova, V. Glebov, V. Erofeeva, S.Yablochnikov, L.Bogdan, E3S Web of Conf. APEEM-2020, 04004 (2020)

6. A. A. Karelin, Psychological tests (Vlados, Moscow, 2003).

7. M. Malik, Eur. Heart J., 17, 354 (1996)

8. N. E. Krylova, State and Law, 4, 32-39 (2007)

9. O. Chudinovskikh, M. Denisenko, E. Donets, Migration intentions of graduates of higher educational institutions: Methods of conducting and the main results of a sample survey (MAKS Press, Moscow, 2003)

10. A. E. Severin, V. V. Rozanov, Medical and technical technologies on the guard of health Collection of reports, 57-58 (2017)

11. R. Anuradha, R. Dutta, J.D. Raja, P. Sivaprakasam, A.B. Patil, Ind. J. of community medicine: official publication of Indian Association of Preventive \& Social Medicine, 42(4), 222-225 (2017)

12. S. Sarkar, R. Gupta, V. Menon, J. of Mental Health and Human Behaviour, 22(2), 8896 (2017)

13. N.P. von der Embse, B.K. Schultz, J.D. Draughn, School Psychology Int., 36(6), 620$37(2015)$ 